\title{
Clinical value of histologic endometrial dating for personalized frozen-thawed embryo transfer in patients with repeated implantation failure in natural cycles
}

Yuan $\mathrm{Li}^{1,2,3}$, Xiao feng $\mathrm{Li}^{1,2}$, Jing nan Liao ${ }^{1,3}$, Xiang xiu Fan ${ }^{1,3}$, Yong bin $\mathrm{Hu}^{4}$, Runxin Gan ${ }^{2}$, Guangxiu Lư ${ }^{2,3}$, Ge Lin ${ }^{1,2,3}$ and Fei Gong ${ }^{1,2,3^{*}}$

\begin{abstract}
Background: Displacement of the window of implantation (WOI) has been proposed as an important factor contributing to repeated implantation failure (RIF). However, the use of histologic endometrial dating as a diagnostic tool of endometrial receptivity has been questioned.

Methods: This study is a prospective intervention trial that enrolled 205 infertile patients from July 2017 to December 2017. Endometrial biopsies from 50 patients with good prognoses were conducted on day $3(n=6), 5$ $(n=6), 7(n=26), 9(n=6)$, or $11(n=6)$ post-ovulation (PO +3/5/7/9/11) of the previous natural cycle before their conventional frozen-thawed embryo transfer (FET) cycle. We conducted endometrial biopsies for 155 RIF patients on day $\mathrm{PO}+7$.

Results: The verification of the Noyes criteria for endometrial dating was conducted at different times $(\mathrm{PO}+3 /+5 /$ $+7 /+9 /+11$ ) on 41 patients with good prognoses who achieved an ongoing pregnancy in their first conventional FET cycle after endometrial biopsy. The agreement between two pathologists determining endometrial biopsy dating results in infertile patients was determined to be acceptable (weighted kappa $=0.672, P<0.001$ ). The rate of out-of-phase dating on day PO + 7 was significantly higher in RIF patients than in good- prognosis patients (31.6\% vs. $3.8 \%, P=0.003)$. pFET was performed in 47 RIF patients diagnosed to be out of phase, and the cumulative livebirth rate was $61.7 \%$.
\end{abstract}

Conclusions: Histologic endometrial dating of RIF patients in natural cycles may be a biomarker for a receptive endometrium in diagnosing WOI displacement.

\footnotetext{
* Correspondence: gongfei0218@hotmail.com

${ }^{1}$ Institute of Reproduction and Stem Cell Engineering, Basic Medicine

College, Central South University, Changsha, China

${ }^{2}$ Reproductive and Genetic Hospital of CITIC-XIANGYA, Changsha, China

Full list of author information is available at the end of the article
}

(C) The Author(s). 2020 Open Access This article is licensed under a Creative Commons Attribution 4.0 International License, which permits use, sharing, adaptation, distribution and reproduction in any medium or format, as long as you give appropriate credit to the original author(s) and the source, provide a link to the Creative Commons licence, and indicate if changes were made. The images or other third party material in this article are included in the article's Creative Commons licence, unless indicated otherwise in a credit line to the material. If material is not included in the article's Creative Commons licence and your intended use is not permitted by statutory regulation or exceeds the permitted use, you will need to obtain permission directly from the copyright holder. To view a copy of this licence, visit http://creativecommons.org/licenses/by/4.0/ The Creative Commons Public Domain Dedication waiver (http://creativecommons.org/publicdomain/zero/1.0/) applies to the data made available in this article, unless otherwise stated in a credit line to the data. 


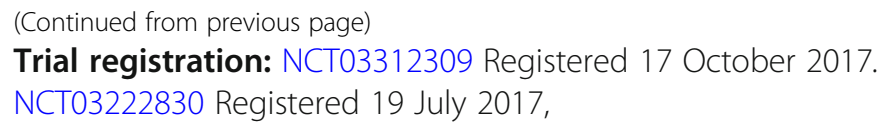

Keywords: Histologic endometrial dating, Endometrial receptivity, Personal embryo transfer, Window of implantation

\section{Background}

Repeated implantation failure (RIF) is a particular challenge that is defined as the absence of a gestational sac at five or more weeks after an embryo transfer (ET) subsequent to three previous embryo transfers with highquality embryos, or after the transfer of $\geq 10$ embryos in multiple transfers [1]. RIF can be caused by both maternal and embryonic factors [2], and blastocyst culture and preimplantation genetic screening can partially improve pregnancy outcome through better embryo selection [3]. The uterus, an important player in implantation, may be affected by polyps, intrauterine adhesions, uterine fibroids, adenomyosis, endometritis, and uterine malformations, and has been demonstrated to contribute to embryonic implantation failure [4]. Different strategies have been developed to improve pregnancy outcomes for the aforementioned diseases, but unexplained RIF remains a challenge.

Endometrial receptivity has been frequently evaluated as one of the many uterine factors involved in RIF, but the relationship remains controversial. Several endometrial markers, such as the presence of pinopods, immunohistochemical biomarkers, and endometrial waves and blood flow, have been used to determine uterine receptivity. These biomarkers may interact transiently with the embryo at implantation, but they appear to be unreliable for evaluating receptivity, particularly as precision indicators for use as clinical diagnostic tools [5-7].

The endometrium becomes receptive to implantation as a result of a series of timed hormonal events during the menstrual cycle. Endometrial exposure to progesterone after ovulation initiates morphological and functional alterations, triggering a shift from a pre-receptive state to a receptive state. With the secretion of progesterone, subnuclear vacuoles, which are found in epithelial cells during the early secretory phase, discharge the secretory products within their glandular epithelium cells to the glandular lumen, and stromal edema becomes maximal in the middle secretory phase, all of which contributes to blastocyst adhesion and invasion. In this phase, edema is also less marked, and a predecidual reaction begins around the blood vessels, contributing to embryonic implantation. The morphological changes observed histologically for each specific day after ovulation were described by Noyes and his colleagues in 1950, and termed the Noyes criteria [8]. An endometrial biopsy that shows a difference of more than 2 days between the histologic dating and actual day after ovulation is considered to be "out of phase" [9]. However, the clinical application of the Noyes criteria is relatively limited, as an out-of-phase endometrium has also been found in $5-50 \%$ of fertile patients [10-12]. The large variation in researchers' results may be due to inaccurate determination of the ovulation day.

Previous investigators demonstrated that classic histologic dating of endometrial biopsy samples could be used to estimate the timing of the window of implantation and to adjust embryonic transfer time [13]. This in turn could potentially increase the implantation rate of patients with an out-of-phase endometrium during hormone replacement therapy (HRT) cycles [13]. The clinical value of histologic endometrial dating in RIF patients during natural cycles, however, has yet to be determined. In the present study, we investigated the clinical effects of personalized frozen-thawed embryo transfer (pFET) in patients with unexplained RIF using histologic dating of endometrial biopsies, which were performed under ultrasound-guided ovulation monitoring during natural cycles.

\section{Methods}

\section{Study population}

In this pilot study, we evaluated a total of 205 infertile patients and created two phases. In phase I, a total of 50 patients with good prognoses underwent endometrial biopsy at different time-points $(\mathrm{PO}+3 / 5 / 7 / 9 / 11)$ (Fig. 1). The histological profiles of good-prognosis patients who were pregnant in their first conventional FET cycle were then collected as fertility parameters. For the goodprognosis patient group, we enrolled women aged 20-35 who underwent FET in a natural cycle. In phase II, 155 patients with unexplained RIF were recruited for endometrial dating evaluation on $\mathrm{PO}+7$ (Fig. 1). According to an ESHRE PGD consortium, RIF was defined as the absence of a gestational sac upon ultrasonographic examination at five or more weeks subsequent to three embryo transfers with high-quality embryos, or after the transfer of $\geq 10$ embryos in multiple transfers [1]. Patients with uterine abnormalities (double uterus, bicornuate uterus, unicornuate uterus, and uterine mediastinum), intrauterine adhesions, endometriosis, adenomyosis, hydrosalpinx, or uterine fibroids (submucosal 


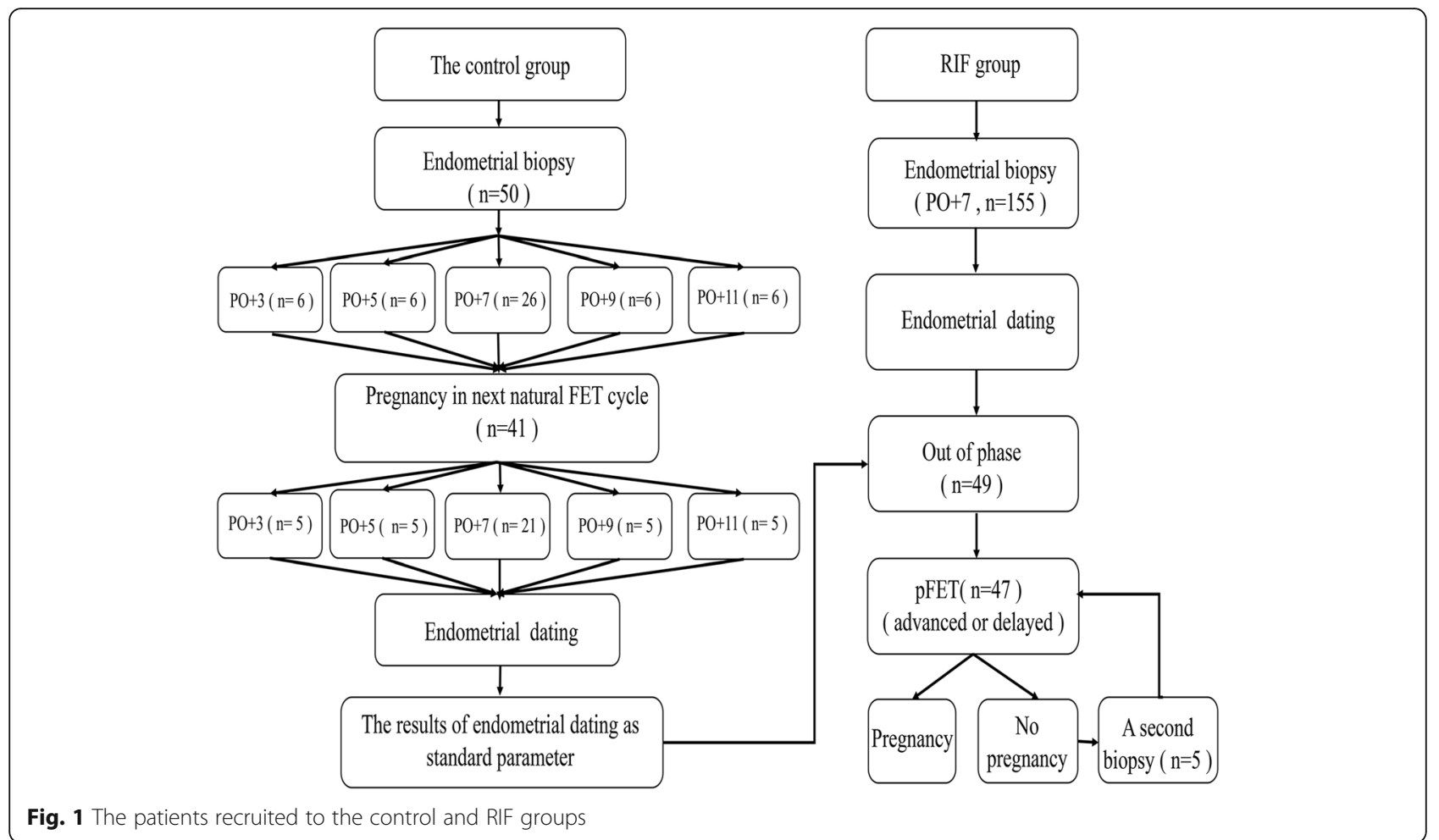

fibroids, non-mucosal fibroids $>4 \mathrm{~cm}$ and/or endometrial pressure) were excluded from the unexplained-RIF group. In both groups, patients demonstrated a menstrual cycle length of 24-35 days and an indication for ovarian stimulation before in vitro fertilization/intracytoplasmic sperm injection (IVF/ICSI). This study was approved by the Ethics Committee of the Reproductive and Genetic Hospital of CITIC-XIANGYA (LL-SC2017-007) (June 29, 2017). Although we began to recruit the patients on the initial release date of our clinical trial, we discovered the advantages of histologic dating of endometrial biopsy samples when we designed and organized the data of the first clinical trial (NCT03222830). We then increased the sample size of our study, which was of major importance in recruiting RIF patients and good-prognosis patients for histologic dating for the second clinical trial (NCT03312309).

\section{Ovulation monitoring}

All patients were monitored throughout a natural cycle, with a daily ultrasonographic scan from the 10th-12th days of the menstrual cycle when the largest follicular diameter was $16 \mathrm{~mm}$, and until the dominant follicle disappeared. Urinary LH concentrations were assessed simultaneously when the follicular diameter was $16 \mathrm{~mm}$. The day of dominant follicle disappearance was considered to be the day of ovulation (post-ovulation $+0, \mathrm{PO}+0$ ).

\section{Endometrial biopsy}

Endometrial biopsy was performed using a sterile pipelle (Laboratory CCD, China), and the tissue was stored in Hank's Balanced Salt Solution (Life Technologies, Grand Island, NY) on ice for further processing.

\section{Histologic analysis and dating}

Endometrial tissue was rinsed in chilled PBS, followed by fixation and paraffin embedding (FFPE) with 10\% neutral-buffered formalin. FFPE tissues were sectioned at a $6 \mathrm{~mm}$ thickness for hematoxylin and eosin (H\&E) staining. All $\mathrm{H} \& \mathrm{E}$-stained endometrial biopsies were analyzed in a blinded manner to evaluate endometrial dating and glandular and stromal development. The endometrial dating was verified according to the Noyes dating criteria [8].

\section{Personal frozen embryo transfer/conventional frozen embryo transfer protocol}

For the FET cycle, no more than two embryos were transferred to each patient. Embryos were warmed using a commercially available warming solution (Kitazato Biopharma), according to the Kuwayama kit instructions [14]. After warming, embryos were transferred to G1.5/ G2.5 medium and cultured for 2-6h. Only cleavagestage embryos that exhibited $>50 \%$ intact blastomeres or blastocysts that re-expanded after warming were considered as surviving and suitable for transfer. For patients with good prognoses, the cleavage-stage embryos or 
blastocysts were transferred either 3 or 5 days, respectively, after ovulation, regardless of endometrial dating. For the RIF group, they were transferred 4-7 days after ovulation, depending upon the endometrial dating results. We applied luteal support when the dominant follicle disappeared, and when we observed satisfactory endometrial development (thickness $\geq 8 \mathrm{~mm}$ as confirmed by ultrasonographic examination), we administered $40 \mathrm{mg}$ of dydrogesterone (Abbott Biologicals B.V.) until the 28th day of embryo transfer if a pregnancy test was positive.

\section{Clinical outcomes and statistical analysis}

We defined the cumulative live-birth rate of repeated FET cycles during the study period as the probability of a live birth from all patients during the study period. Ongoing pregnancy was defined as at least one intrauterine gestational sac with cardiac activity by ultrasonography performed 6 weeks after ET. Biochemical pregnancy was defined as a positive hCG test in the absence of an intrauterine gestational sac. Analyses were performed using the statistical package SPSS, version 19.0 (SPSS) or $\left(\mathrm{SAS}^{\circ}\right)$ version 9.3 (SAS Institute, Inc., Cary, NC, USA). Continuous variables are presented as the mean \pm standard deviation (SD), and comparisons were made using a one-way ANOVA or non-parametric statistical tests. Categorical data are presented as a number $(\mathrm{N})$ and percentage (\%), and comparisons were made using a Chi-square or Fisher Exact Probability test. A weighted kappa statistic was calculated to summarize the overall agreement between pathologist $\mathrm{A}$ and pathologist B. Bland-Altman plots were drawn to evaluate systematic biases of endometrial dating between pathologists A and B. We used GraphPad Prism7.0 to evaluate the intra-group difference (mean $\pm \mathrm{SD}$ ) in the control group. $P<0.05$ was considered to be statistically significant.

\section{Results}

\section{Noyes criteria verification}

Standard endometrial histologic dating parameters were established from the patients with good prognoses who were pregnant in their first conventional FET cycle $(n=$ 41). All the good-prognosis patients with ongoing pregnancies included in this study went on to have a live birth. With respect to PO dating +3 , glandular nuclei were pushed to the center of the epithelial cells with cytoplasm above and vacuoles below. For PO dating +4 , glandular nuclei returned to the basilar side of the cell. We noted that wisps of secretory material appeared in the lumina, and some vacuoles were pushed past the nucleus, apparently emptying their glycogen into the lumen. Mitosis and pseudostratification of nuclei were absent. For PO dating +5 , only a few vacuoles remained.
For PO dating +7 , tissue edema, although variable in the proliferative phase, was characteristically notable in the mid-secretory stage, becoming evident rather suddenly. For PO dating + 9, the spiral arterioles (which were previously somewhat difficult to distinguish in the edematous stroma) became much more prominent. For PO dating +11 , pre-decidua began to differentiate under the surface epithelium (Fig. S1). These results were consistent with the Noyes dating criteria [8].

\section{Endometrial dating criteria and blinded pathologist agreement}

All endometrial dating $(n=205)$ was determined by two experienced pathologists. The inter-observer agreement was determined to be good (weighted kappa $=0.672$; 95\% CI 0.606-0.737; $P<0.001)$. As shown in Fig. 2, Bland-Altman (B-A) plots of pathologist A and pathologist $\mathrm{B}$ highlighted trends regarding differences in endometrial dating between the two pathologists. The limits of agreement indicated that the difference value for dating an endometrial biopsy was $\leq 1.76$, but that the endometrial dating by both pathologists was clinically consistent when the value was $\leq 2$. Thus, the B-A plots suggested that agreement was good between pathologists $A$ and $B$ when the value was $\leq 2$ using the Noyes criteria in the same patients.

\section{Out-of-phase endometrial dating}

Endometrial dating standards for different days $(\mathrm{PO}+3 /$ $5 / 7 / 9 / 11)$ were established in good-prognosis patients who achieved an ongoing pregnancy in their first conventional FET cycle $(n=41)$ (Fig.1). Two experienced pathologists confirmed the endometrial dating using the Noyes criteria in the good-prognosis patient group, showing that endometrial dating on different PO days to be significantly different. In contrast, the inner-group differences were so small that the endometrial dating of most good-prognosis patients showed a mean \pm SD between the lower and upper limits. The exception was only one endometrium of a good-prognosis patient that was biopsied on $\mathrm{PO}+7$, but was dated as $\mathrm{PO}+3$, and this patient was pregnant in a conventional FET cycle (Fig. 3a).

Blinded histologic dating of endometrial biopsies from RIF $(n=155)$ or good-prognosis patients $(n=26)$ before frozen-thawed embryo transfer was performed on day $\mathrm{PO}+7$. The rate of out-of-phase dating on day $\mathrm{PO}+7$ was significantly higher $(31.6 \%$ vs. $3.8 \%, P=0.003)$ in the RIF group relative to the good-prognosis group (Fig. 3b).

On day $\mathrm{PO}+7$, a total of 49 RIF patients were evaluated as being out of phase, and 106 RIF patients were assessed as being in phase. One third $(n=35)$ of inphase patients were dated +7 , while the remainder $(n=$ 71) of in-phase patients were dated +5 . In out-of-phase 


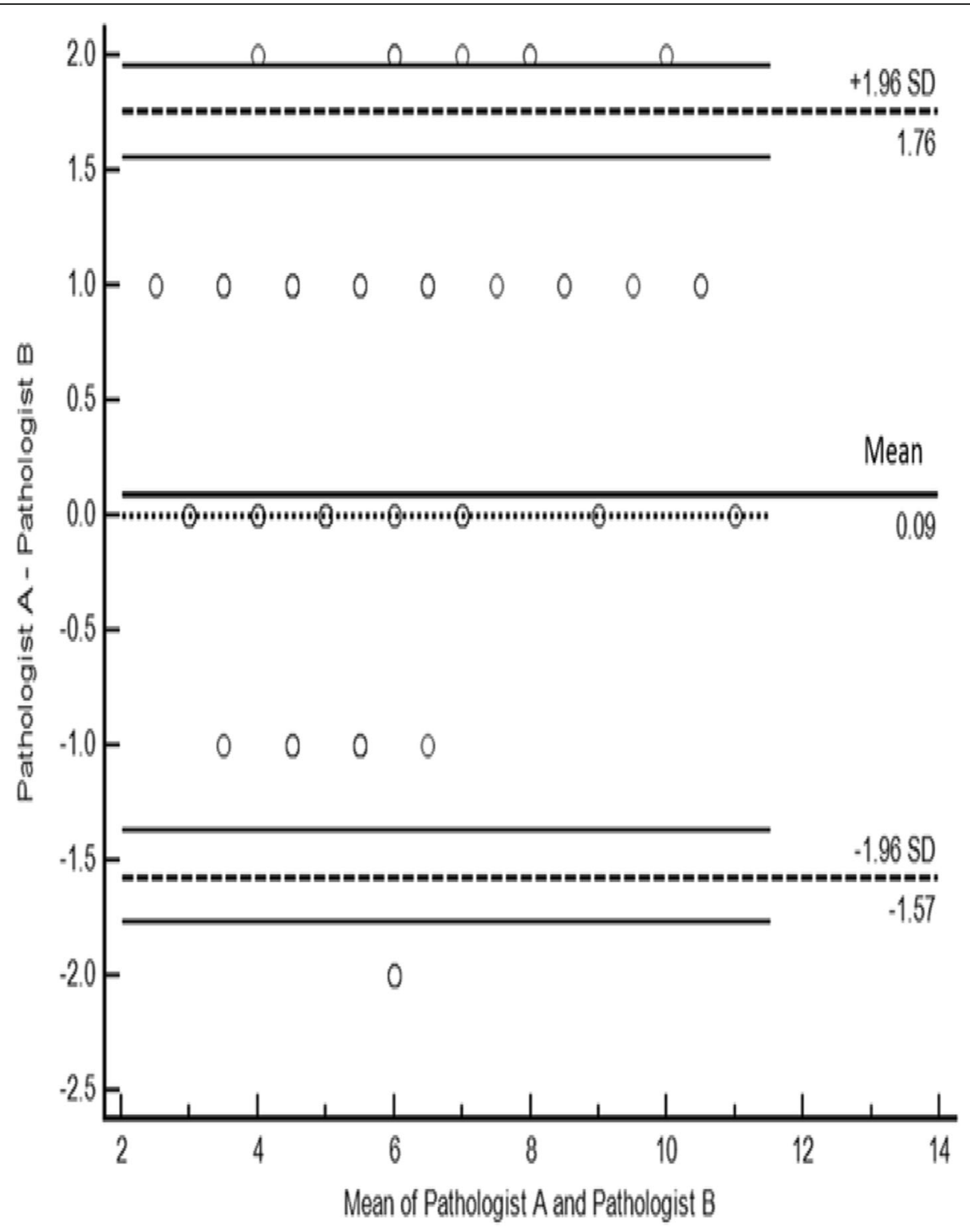

Fig. 2 Bland-Altman plots of variability according to pathologists A and B. The x-axis depicts the mean endometrial sample dating for pathologist $A$ and pathologist $B$; the $y$-axis is the difference from the mean endometrial dating between pathologists $A$ and $B$. The upper and lower lines on the B-A plots represent the limits of agreement and the mean difference \pm 1.96 times its standard deviation. Thus, the distance from 0 and the width of the limits of agreement both indicate the magnitude of disagreement between pathologists. Closer clustering to the mean indicates higher agreement. If the difference value for an endometrial dating is $=0$, then the endometrial dating by pathologist $\mathrm{A}$ and pathologist B was identical

patients, $24 \%(n=12)$ were dated +3 and $73 \%(n=36$, Fig. 3c) were dated +4 (Fig. 3c) or +5 (vacuoles remained) (Fig. 3c), and one patient was diagnosed as dated PO + 10 (Fig. 3c).

\section{Clinical outcomes in RIF patients with endometrial dating results per $\mathrm{pFET}$}

The demographic characteristics and reproductive history of RIF patients, including age, body mass index, duration of infertility, and cause of infertility, are shown in Table 1. Previous failed cycles numbered $3.6 \pm 0.7$, with minimal and maximal values of 3 and 5 cycles, respectively. pFET was performed in 47 patients whose personal window of implantation (WOI) was delayed by $3(n=35)$ or $4(n=11)$ days, or advanced by 3 days $(n=1)$. Day- 3 embryos or Day- 5 blastocysts were then transferred using this strategy in natural cycles after 4 to 7 days of ovulation, resulting in a live-birth rate of $57.4 \%(27 / 47)$ in the first transfer attempt. 


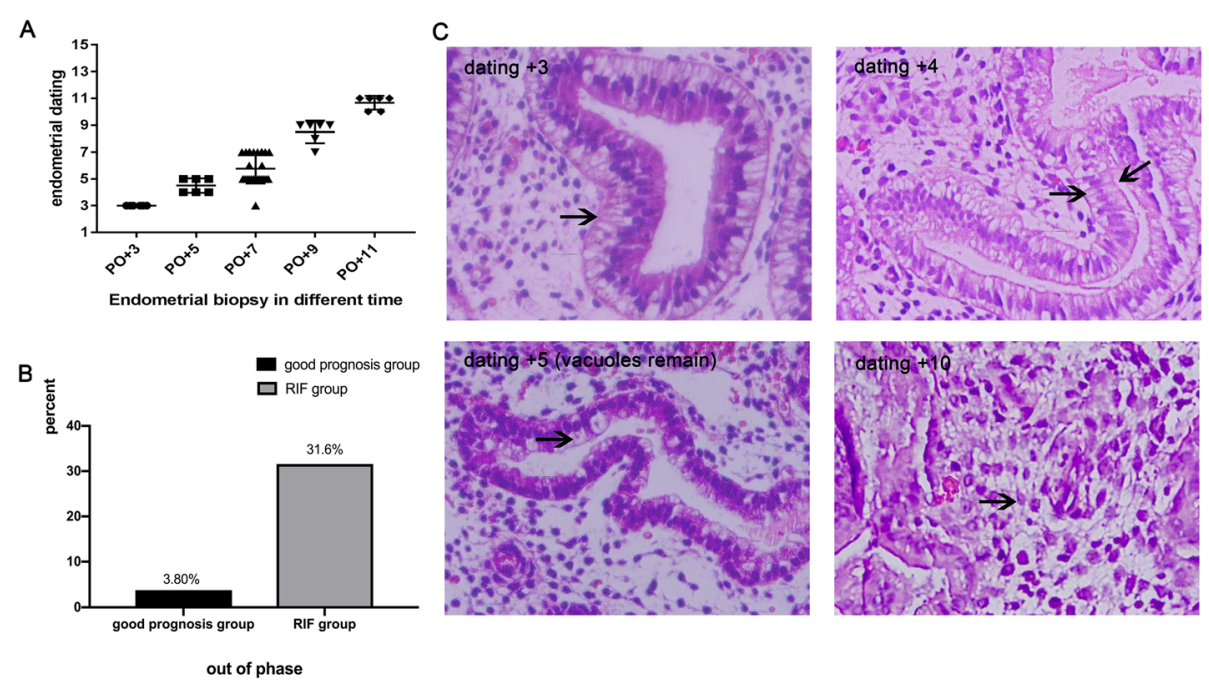

Fig. 3 Endometrial dating in control and RIF groups. a Inner-group differences in endometrial biopsy dating in the control group at different times $(\mathrm{PO}+3 / 5 / 7 / 9 / 11)$ were rare, as proven by two experienced pathologists. Using the mean $\pm \mathrm{SD}$ as the lower and upper limits to define a reference range for endometrial biopsy dating, 1 of 50 control women were below the range. $\mathbf{b}$ The out-of-phase rate in the good-prognosis group was different from that for the RIF group. $\mathbf{c}$ Endometrial dating according to the Noyes criteria in RIF patients ( $X$ 400). Dating +3 , gland cytoplasm and nuclei above and vacuoles below (arrow); dating +4 , glandular nuclei are in the center of the cells and glycogen vacuoles are seen on two sides of the gland nuclei (arrow); dating +5 , vacuoles (arrow) remain in the basement membrane of the gland cells; dating +10 , pre-decidua (arrow) begin to differentiate and spiral arteries increase

RIF patients who failed to become pregnant after the first pFET had a second endometrial biopsy delayed by 1-2 days according to the results of the first round of endometrial dating. All of these five patients then showed their expected endometrial dating result in their second endometrial biopsy. In the second pFET attempt, the live-birth rate was $40 \%(2 / 5)$, and thus the cumulative live-birth rate for personal FET was $61.7 \%$.

\section{Discussion}

Implantation is not a single event, but is more accurately described as a cascade of interactions between the embryo and endometrium. The human endometrium is receptive to embryonic implantation during a narrow period of the menstrual cycle referred to as the WOI. The WOI had been assumed to be constant for all women, although investigators have recently demonstrated the existence of a "displaced WOI" [15-18]. The classic method of dating the endometrium using defined histologic criteria was established in 1950 [8], but pFET studies in natural cycles using the Noyes criteria are presently lacking. In the present study, we established the endometrial dating criteria only for patients who became pregnant in their first conventional FET cycle. All our good-prognosis patients were pregnant, with histologic dating of days $+5-7$ on day $\mathrm{PO}+7$, except for one patient whose histologic dating was $\mathrm{PO}+3$, which is consistent with the in-phase definition [9]. Endometrial dating was simultaneously evaluated by two experienced pathologists, and the inter-observer agreement was statistically determined to be acceptable. Thus, the endometrial dating criteria were easily mastered and utilized according to the Noyes criteria.

Finally, our data indicated that intra-group variation in the good-prognosis patients was so low that we considered our results to be highly reliable. We determined the reproducibility and verifiability of our endometrial dating results in the same patients, with five RIF patients who failed to become pregnant after the first pFET. These patients underwent a second endometrial biopsy delayed by 1 or 2 days according to the results of the first round of endometrial dating, and showed the expected endometrial dating results in the second endometrial biopsy. The second biopsies were conducted within 4 months, which suggested that the endometrial dating results might be repeatable in 4 months. Endometrial dating of a larger sample and longer period of time is still necessary to corroborate reproducibility. Displaced WOI may be detected by endometrial dating, and a subset of the patients with unexplained RIF may benefit from our study data.

This is the first pFET study to utilize endometrial dating verified by the Noyes criteria. First, we verified the Noyes criteria using endometrium samples from different time points from the pregnant good prognosis patients. Second, we compared the difference of the outof-phase rate (displacement of WOI) between RIF patients and good-prognosis patients. Third, we 
Table 1 Summary of the demographic characteristics, reproductive history and the clinical outcomes of RIF patients and control patients

\begin{tabular}{|c|c|c|c|}
\hline & $\begin{array}{l}\text { RIF patients } \\
(n=155)\end{array}$ & $\begin{array}{l}\text { Good prognosis patients } \\
(n=26)\end{array}$ & $P$ value \\
\hline Age(y) & $33.0 \pm 3.7$ & $29.1 \pm 2.8$ & $<0.001$ \\
\hline Duration of infertility (year) & $5.6 \pm 2.6$ & $3.2 \pm 1.9$ & 0.022 \\
\hline BMI (kg/m2) & $20.9 \pm 1.6$ & $21.9 \pm 2.3$ & $<0.001$ \\
\hline Basal FSH level (mlU/ml) & $6.4 \pm 2.7$ & $5.6 \pm 1.5$ & 0.131 \\
\hline Endometrial thickness on the day of embryo transfer & $11.5 \pm 1.5$ & $11.1 \pm 2.2$ & 0.263 \\
\hline Cause of infertility & & & 0.367 \\
\hline Male factor & 20/155(12.9\%) & $5 / 26(19.3 \%)$ & \\
\hline Tubal factor & 135/155 (87.1\%) & $21 / 26(80.7 \%)$ & \\
\hline No. of previous failed cycles & $3.6 \pm 0.7$ & 1 & / \\
\hline The out of phase rate & 49/155 (31.6\%) & $1 / 26(3.8 \%)$ & 0.003 \\
\hline Total patients with 1st pFET/FET & 47 & 26 & \\
\hline High quality embryo rate & $33 / 47(70.2 \%)$ & 20/26 (76.9\%) & 0.793 \\
\hline Cleavage stage embryo & $3 / 47(6.4 \%)$ & $3 / 26(11.5 \%)$ & \\
\hline Blastocyst & $30 / 47(63.8 \%)$ & $17 / 26(65.4 \%)$ & \\
\hline Implantation rate after 1st pFET/FET & $32 / 67(47.8 \%)$ & 23/41 (56.1\%) & 0.400 \\
\hline Ongoing pregnancies rate after 1st pFET/FET & 29/47 (61.7\%) & $21 / 26(80.7 \%)$ & 0.093 \\
\hline Biochemical pregnancies after 1st pFET & $7 / 47$ (14.9\%) & $2 / 26(7.6 \%)$ & 0.476 \\
\hline live birth rate after 1st pFET/FET & $27 / 47(57.4 \%)$ & $21 / 26(80.7 \%)$ & 0.07 \\
\hline Failed pregnancies after 1st pFET/FET & 11 & 3 & \\
\hline No. of 2 nd biopsies at the specified day & 5 & / & \\
\hline 2nd expectant endometrial dating & 5 & / & \\
\hline Total patients with 2nd pFET/FET & 5 & 2 & \\
\hline Implantation rate after 2nd pFET/FET & $3 / 7(42.8 \%)$ & 0 & \\
\hline Ongoing pregnancies after 2nd pFET/FET & $3 / 5(60 \%)$ & 0 & \\
\hline Accumulative live birth rate after pFET/FET & $29 / 47(61.7 \%)$ & $21 / 26(80.7 \%)$ & 0.093 \\
\hline
\end{tabular}

determined individualized interventions (pFET) based on the verified criteria.

There were some limitations to our research. Although the results of previous donor oocyte IVF cycles suggested that recipients age $\leq 39$ years had similar rates of implantation, clinical pregnancy, and live birth [19], we couldn't exclude the impact of age on endometrial dating by recruiting younger female (20-35 years) patients for the good-prognosis group. The primary objective of our study was to use endometrial histology to detect WOI displacement in RIF patients, and to evaluate the clinical outcomes by pFET. However, there were no comparative data on clinical pregnancy rates or live-birth rates in women with RIF who had an adjusted FET, or on those who did not. We suggest that a randomized controlled study for RIF patients with out-of-phase dating be undertaken, and that further research be performed to determine the mechanism(s) underlying irregularities in the WOI.

\section{Conclusions}

We observed an obviously increased percentage in WOI displacement in RIF patients compared with goodprognosis patients, leading us to propose $\mathrm{pFET}$ as a treatment strategy. FET personalized according histologic endometrial dating may improve the clinical outcomes of patients with unexplained RIF.

\section{Supplementary information}

Supplementary information accompanies this paper at https://doi.org/10 1186/s12884-020-03217-y.

Additional file 1: Figure S1. Endometrial specimen dating according to Noyes criteria (X 400). A (dating +3 ), gland nuclei were pushed to the center of the epithelial cells, with the cytoplasm above and vacuoles below (arrow). B (dating +4 ), gland nuclei returned to the basilar side of the cells, and some vacuoles (arrow) were pushed past the nucleus to apparently empty glycogen into the lumen. $C$ (dating +5 ), few vacuoles remained, and the glandular cavity was filled with secretions (arrow). D (dating +7$)$, tissue edema. E (dating +9 ), glands were highly distorted, jagged, or cauliflower-shaped (arrow). F (dating +11 ), pre-decidua (arrow) began to differentiate under the surface epithelium. 


\section{Abbreviations}

pFET: personalized frozen-thawed embryo transfer; RIF: repeated implantation failure; WOI: window of implantation; PO: post-ovulation; ET: embryo transfer; HRT: hormone-replacement cycle; IVF/ICSI: in vitro fertilization/intracytoplasmic sperm injection; ERA: endometrial receptivity array

\section{Acknowledgments}

We wish to thank the patients who agreed to the collection of their endometrial issues, and we also wish to thank the pathologists who agreed to participate in the procedures described herein.

\section{Authors' contributions}

All authors have read and approved the manuscript. YL designed the experiment, recruited the samples, analyzed histologic samples, and wrote the manuscript; $X F L$ performed the experiment; $L J L, X X F$, and $R X G$ organized the data; $Y$ BH analyzed histologic samples; $G X L$ designed the experiment; and $\mathrm{GL}$ and $\mathrm{FG}$ designed and guided the experiment.

\section{Funding}

The National Science Foundation of China (81501328). The funding organization had no role in the design of the study, data collection, analysis, interpretation of the data, or in the writing of this manuscript.

\section{Availability of data and materials}

The datasets used and/or analyzed during the current study are available from the corresponding author upon reasonable request.

\section{Ethics approval and consent to participate}

The study was approved by the Ethics Committee of the Reproductive and Genetic Hospital of CITIC-XIANGYA (LL-SC-2017-007) (June 29, 2017). Written informed consent was obtained from all participants.

\section{Consent for publication}

Not applicable.

\section{Competing interests}

The authors declare that they have no competing interests.

\section{Author details}

'Institute of Reproduction and Stem Cell Engineering, Basic Medicine College, Central South University, Changsha, China. ${ }^{2}$ Reproductive and Genetic Hospital of CITIC-XIANGYA, Changsha, China. ${ }^{3}$ Key Laboratory of Stem Cells and Reproductive Engineering, National Health and Family Planning Commission, Changsha, China. ${ }^{4}$ Department of Pathology, Xiang Ya Hospital, Central South University, Changsha 410008, China.

Received: 27 September 2019 Accepted: 27 August 2020

Published online: 11 September 2020

\section{References}

1. Harton G, Braude P, Lashwood A, Schmutzler A, Traeger-Synodinos J, Wilton L, Harper JC, European Society for Human Reproduction and Embryology (ESHRE) PGD Consortium. ESHRE PGD consortium best practice guidelines for organization of a PGD Centre for PGD/preimplantation genetic screening. Hum Reprod. 2011;26(1):14-24.

2. Coughlan C, Ledger W, Wang Q, Liu F, Demirol A, Gurgan T, Cutting R, Ong K, Sallam H, Li TC. Recurrent implantation failure: definition and management. Reprod BioMed Online. 2014;28(1):14-38.

3. Minasi MG, Fiorentino F, Ruberti A, Biricik A, Cursio E, Cotroneo E, Varricchio MT, Surdo M, Spinella F, Greco E. Genetic diseases and aneuploidies can be detected with a single blastocyst biopsy: a successful clinical approach. Hum Reprod. 2017;32(8):1770-7.

4. Achache $\mathrm{H}$, Revel A. Endometrial receptivity markers,the journey to successful embryo implantation. Hum Reprod Update. 2006;12(6):731-46.

5. Aghajanova L, Hamilton AE, Giudice LC. Uterine receptivity to human embryonic implantation: histology, biomarkers, and transcriptomics. Semin Cell Dev Biol. 2008;19(2):204-11.

6. Nardo LG, Nikas G, Makrigiannakis A, Sinatra F, Nardo F. Synchronous expression of pinopodes and alpha $v$ beta 3 and alpha 4 beta 1 integrins in the endometrial surface epithelium of normally menstruating women during the implantation window. J Reprod Med. 2003;48(5):355-61.

7. Lessey BA. Two pathways of progesterone action in the human endometrium: implications for implantation and contraception. Steroids. 2003 Nov;68(10-13):809-15.

8. Noyes RW, Hertig Al, Rock J. Dating the endometrial biopsy. Fertil Steril. 1950;1:3-25.

9. Wentz AC. Endometrial biopsy in the evaluation of infertility. Fertil Steril. 1980;33:121-4.

10. Sahmay S, Oral E, Saridogan E, Senturk L, Atasu T. Endometrial biopsy findings in infertility: analysis of 12,949 cases. Int J Fertil Menopausal Stud. 1995;40(6):316-21.

11. Zawar MP, Deshpande NM, Gadgil PA, Mahanta AA. Histopathological study of endometrium in infertility. Indian J Pathol Microbiol. 2003;46(4):630-3.

12. Coutifaris C, Myers ER, Guzick DS, Diamond MP, Carson SA, Legro RS, et al. Histological dating of timed endometrial biopsy tissue is not related to fertility status. Fertil Steril. 2004;82(5):1264-72.

13. Gomaa H, Casper RF, Esfandiari N, Bentov Y. Non-synchronized endometrium and its correction in non-ovulatory cryopreserved embryo transfer cycles. Reprod BioMed Online. 2015;30(4):378-84.

14. Kuwayama M. Highly efficient vitrification for cryopreservation of human oocytes and embryos: the Cryotop method. Theriogenology. 2007;67(1): 73-67 80.

15. Lessey BA. Assessment of endometrial receptivity. Fertil Steril. 2011;96(3): 522-9.

16. Galliano D, Bellver J, Díaz-García C, Simón C, Pellicer A. ART and uterine pathology: how relevant is the maternal side for implantation? Hum Reprod Update. 2015;21(1):13-38.

17. Kliman HJ, Frankfurter D. Clinical approach to recurrent implantation failure: evidence-based evaluation of the endometrium. Fertil Steril. 2019;111(4):618-28

18. Paulson RJ. Introduction: endometrial receptivity: evaluation, induction and inhibition. Fertil Steril. 2019;111(4):609-10.

19. Yeh JS, Steward RG, Dude AM, Shah AA, Goldfarb JM, Muasher SJ. Pregnancy outcomes decline in recipients over age 44: an analysis of 27,959 fresh donor oocyte in vitro fertilization cycles from the Society for Assisted Reproductive Technology. Fertil Steril. 2014;101(5):1331-6.

\section{Publisher's Note}

Springer Nature remains neutral with regard to jurisdictional claims in published maps and institutional affiliations.
Ready to submit your research? Choose BMC and benefit from:
- fast, convenient online submission
- thorough peer review by experienced researchers in your field
- rapid publication on acceptance
- support for research data, including large and complex data types
- gold Open Access which fosters wider collaboration and increased citations
- maximum visibility for your research: over $100 \mathrm{M}$ website views per year
At BMC, research is always in progress.
Learn more biomedcentral.com/submissions 